\title{
Therapeutic Effects of Hybrid Liposomes Against Xenograft Mouse Model of Colorectal Cancer In Vivo Due to Long-term Accumulation
}

\author{
HIDEAKI ICHIHARA, MASAKI OKUMURA and YOKO MATSUMOTO \\ Division of Applied Life Science, Graduate School of Engineering, Sojo University, Kumamoto, Japan
}

\begin{abstract}
Aim: To examine therapeutic effects of hybrid liposomes (HL) composed of $L$ - $\alpha$-dimyristylphosphatidylcholine (DMPC) and polyoxyethylene (25) dodecyl ether $\left(C_{12}(E O)_{25}\right)$ against human colorectal cancer (WiDr) cells in vitro and in vivo. Materials and Methods: HL composed of 90

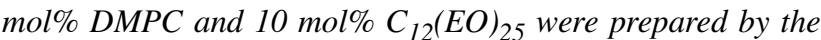
sonication method. Therapeutic effects of $H L$ in the subcutaneous xenograft model mice of colorectal cancer were examined in vivo. Results: Inhibitory effects of HL on the growth of WiDr cells were obtained along with apoptosis measurement. Selective accumulation of HL, including a fluorescence probe (indocyanine green; (ICG)), was observed for WiDr cells using a fluorescence microscope. Remarkable reduction of tumor volume in xenograft model of mice topically HL-treated without drugs after the subcutaneous inoculation of WiDr cells was verified in vivo. Induction of apoptosis in tumor cells of xenograft mice topically administered with $H L$ was observed in micrographs on the basis of terminal deoxynucleotidyl tranferase-mediated dUTP-biotin nick end labeling (TUNEL) method. Accumulation of HL, including ICG, for long-term into the tumor was obtained in the xenograft model. Conclusion: Therapeutic effects of $H L$ without any drugs in the murine xenograft model after subcutaneous inoculation of human colorectal cancer were revealed for the first time in vivo due to long-term accumulation.
\end{abstract}

It is well known that the colorectal cancer is one of the cancers having high mortality worldwide. The number of

Correspondence to: Yoko Matsumoto, PhD, Division of Applied Life Science, Graduate School of Engineering, Sojo University, 422-1, Ikeda, Nishi-ku, Kumamoto, 860-0082, Japan. Tel: +81 963263965, Fax: +81 963261331, e-mail: matumoto@life.sojou.ac.jp

Key Words: Hybrid liposome, chemotherapy, colorectal cancer, apoptosis, selective accumulation. patients having colorectal cancer is increasing each year in accordance with the increase of cancer risks, such as smoking, alcohol and obesity. Surgical resection of the tumor is most effective for achieving a complete cure for patients with colorectal cancer on the early stages. Chemotherapy is selected for postoperative advanced colorectal cancer since the surgical resection is not effective for advanced stages of the disease. Combination chemotherapy is often used for advanced colorectal cancer. However, combination chemotherapy has severe side-effects (1-4). Therefore, the development of chemotherapeutic regiments without sideeffects is desired. The diagnosis of colorectal cancer is performed based on an examination, such as colonoscopy, biopsy, tumor marker, magnetic resonance imaging (MRI) and positron emission tomography (PET). Studies of less invasive diagnostic procedures without the physical burden for the patients are being conducted to improve patient satisfaction and quality of life.

Hybrid liposomes (HL) $(5,6)$ can simply be prepared by sonication of vesicular and micellar molecules in a buffer solution, unlike general liposomal preparation method. Effective drug delivery systems using HL as drug carrier has been obtained in the treatment of brain tumors (7) and duchenne muscular dystrophy (8). High inhibitory effects of HL on the growth of various tumor cells in vitro along with the induction of apoptosis have been obtained without using drugs (9-11). Remarkable therapeutic effects of HL were demonstrated on the growth of tumor cells in vivo (12-15). No toxicity of HL was observed in normal rats in vivo nor were there any side-effects (12-13). After receiving the approval of the Bioethics Committee, successful clinical chemotherapy with drug-free HL to patients with lymphoma has been reported (12). In addition, fusion and accumulation of HL, including a fluorescence probe for human hepatoma (Hep-G2) cells, has also been reported (16).

In this study, we examined the antitumor effects of HL composed of L- $\alpha$-dimyristoylphosphatidylcholine (DMPC) and polyoxyethylene (25) dodecyl ether $\left(\mathrm{C}_{12}(\mathrm{EO})_{25}\right)$ for human colorectal cancer (WiDr) cells along with apoptosis in vitro. 
We investigated the therapeutic effects of HL on a murine xenograft model after the subcutaneous inoculation of WiDr cells in vivo.

\section{Materials and Methods}

Preparation of $H L$. HL were prepared by sonication of a mixture containing $90 \mathrm{~mol} \% \mathrm{~L}-\alpha$-dimyristoylphosphatidylcholine (DMPC; NOF, Tokyo, Japan) and 10 mol\% polyoxyethylene (25) dodecyl ether $\left(\mathrm{C}_{12}(\mathrm{EO})_{25}\right.$; Nikko Chemicals, Tokyo, Japan) in $5 \%$ glucose solution using bath-type sonicator (VS-N300; VELVO-CLEAR, Tokyo, Japan) at $45^{\circ} \mathrm{C}$ with $300 \mathrm{~W}$ and filtered with a $0.20 \mu \mathrm{m}$ cellulose acetate filter (Advantec, Tokyo, Japan).

Dynamic light scattering measurement. The diameter of HL was measured with a light scattering spectrometer (ELSZ-0; Otsuka Electronics, Osaka, Japan) using a He-Ne laser $(633 \mathrm{~nm})$ at a $90^{\circ}$ scattering angle. The hydrodynamic diameter $\left(d_{\mathrm{hy}}\right)$ was calculated using the Stokes-Einstein formula (Equation 1), where $k$ is the Boltzmann constant, $T$ is the absolute temperature, $\eta$ is the viscosity and $D$ is the diffusion coefficient:

\section{$\mathrm{d}_{\text {hy }}=\mathrm{KT} / 3 \pi \eta \mathrm{D}$ (Equation 1)}

Cell culture. Human colorectal cancer (WiDr) cell line was purchased from the American Type Culture Collection (Manassa, VA, USA). WiDr cells were maintained in minimum essential medium (MEM; Gibco BRL, Rockville, MD, USA) supplemented with $1 \%$ non-essential amino acids (NEAA), penicillin $100 \mathrm{U} / \mathrm{ml}$, streptomycin $50 \mu \mathrm{g} / \mathrm{ml}$ and $10 \%$ fetal bovine serum (FBS; HyClone, Omaha, NE, USA). The cells were cultured in a $5 \% \mathrm{CO}_{2}$ humidified incubator at $37^{\circ} \mathrm{C}$.

Assessment of $50 \%$ inhibitory concentration $\left(I_{50}\right)$ in vitro. The $\mathrm{IC}_{50}$ on the growth of tumor cells was determined on the basis of WST-8 [2-(2-methoxy-4-nitrophenyl)-3-(4-nitrophenyl)-5-(2,4-disulfophenyl)$2 \mathrm{H}$ tetrazolium, monosodium salt] assay (Cell Counting Kit-8; Dojindo Laboratories, Kumamoto, Japan) (17-18). Cells $\left(5.0 \times 10^{4}\right.$ cells $\left./ \mathrm{ml}\right)$ were seeded in 96 -well plates and cultured in a $5 \% \mathrm{CO}_{2}$ humidified incubator at $37{ }^{\circ} \mathrm{C}$ for $24 \mathrm{~h}$. Cells were cultured for a further $48 \mathrm{~h}$ after adding DMPC (0.01-1.0 mM) and HL (0.01-0.5 mM) on the basis of DMPC concentration. WST-8 solution was added and the cells were incubated for $3 \mathrm{~h}$. The absorbance at a wavelength of $450 \mathrm{~nm}$ was measured by spectrophotometer (Emax; Molecular Devices Co., Sunnyvale, CA, USA). The inhibitory effects of $\mathrm{HL}$ on the growth of tumor cells were evaluated by $\mathrm{A}_{\text {mean }} / \mathrm{A}_{\text {control }}$, where $\mathrm{A}_{\text {mean }}$ and $\mathrm{A}_{\text {control }}$ denote the absorbance of water-soluble formazan, in the presence and absence of HL, respectively.

Terminal deoxynucleotidyl tranferase-mediated dUTP-biotin nick end labeling (TUNEL) method in vitro. Detection of apoptotic cells was performed by the TUNEL method using an In Situ Cell Death Detection Kit (Roche Diagnostics, Basel, Switzerland). The WiDr cells $\left(5 \times 10^{4}\right.$ cells $\left./ \mathrm{ml}\right)$ were seeded in dishes and cultured for $24 \mathrm{~h}$. HL ([DMPC $]=0.1 \mathrm{mM},\left[\mathrm{C}_{12}(\mathrm{EO})_{25}\right]=0.011 \mathrm{mM}$ ) or DMPC liposomes were added and cells were cultured for $48 \mathrm{~h}$. Four $\%$ paraformaldehyde solution was added for fixation purposes. After formalin was removed, the cells were washed in Hank's Balanced Salt Solution (HBSS). The impregnated solution was added and the cells were stored in shade at $4{ }^{\circ} \mathrm{C}$ for $2 \mathrm{~min}$. After the cells were washed,
TUNEL reaction mixed-solution was added and cells were incubated at $37^{\circ} \mathrm{C}$ for $60 \mathrm{~min}$ within humectant box. TOPRO-3 (Molecular Probes, Inc., Sunnyvale, OR, USA) was added and the cells were stored in room temperature for $20 \mathrm{~min}$ under the shade condition. The stained cells were observed using a confocal laser microscope (TCSSP; Leica Microsystems, Wetzlar, Germany) with a $488 \mathrm{~nm}$ Ar laser line for TUNEL (detection at 515-565 nm) and $633 \mathrm{~nm} \mathrm{He} / \mathrm{Ne}$ laser line for TOPRO-3 (detection at $640-700 \mathrm{~nm}$ ).

Fusion and accumulation of HL into the tumor cell membrane. The fusion and accumulation of HL, including a fluorescence probe (indocyanine green (ICG); Tokyo Chemical Industry Co., Ltd., Tokyo, Japan) into the membrane of WiDr cells, was performed using fluorescence cell imaging system (EVOS; Thermo Fisher Scientific Inc., Waltham, MA, USA). Cells $\left(5.0 \times 10^{5}\right.$ cells $\left./ \mathrm{ml}\right)$ were cultured in a $5 \% \mathrm{CO}_{2}$ humidified incubator at $37^{\circ} \mathrm{C}$ for $24 \mathrm{~h}$. The cells were treated with $\mathrm{HL}$ ([DMPC] $=0.1 \mathrm{mM},\left[\mathrm{C}_{12}(\mathrm{EO})_{25}\right]=0.012 \mathrm{mM}$, $[\mathrm{ICG}]=0.0047 \mathrm{mM})$, including fluorescence probe for $3 \mathrm{~h}$, and observed using fluorescence cell imaging system $(710 / 40 \mathrm{~nm}$ Excitation; 775/46 nm Emission).

Assessment of therapeutic effects in vivo. The mice were handled in accordance with the guidelines for animal experimentation set out in Japanese law. The animal studies were approved by the Committee on Animal Research of Sojo University. BALB/c-R/J mice were kindly provided by Prof. Okada (Kumamoto University, Japan). (19) The mice were bred in ventilator with 14 fresh-air changes per hour at room temperature $\left(25 \pm 1^{\circ} \mathrm{C}\right)$, humidity $50 \pm 10 \%$ and under a 12 -h light: 12 -h dark illumination cycle. The mice were randomly grouped on the basis of body weight by the stratified randomization method. The number of mice was seven in each group. The WiDr cells $\left(5.0 \times 10^{6}\right.$ cells $)$ were subcutaneously transplanted into the BALB/c-R/J mice. HL (34 mg/kg for DMPC) was topically administered once each day for 14 days from 2days after the inoculation of WiDr cells. The tumor volume was measured using vernier caliper and calculated using the equation of $V=0.5 \times a^{2} \times b$, where $a$ and $b$ denote the smallest and longest superficial diameter, respectively $(13,20-21)$. Then, the subcutaneous tumors were isolated from mouse under anesthesia and weighed.

TUNEL method in vivo. Detection of apoptotic cells was performed on the basis of the TUNEL method using an in situ apoptosis detection kit (ApopTag Plus Peroxidase; Intergen, Burlington, MA, USA) according to manufacturer's directions. WiDr cells $\left(5.0 \times 10^{6}\right.$ cells $)$ in suspension were subcutaneously inoculated into BALB/c-R/J mice. HL was topically administered into mice once each day for 14 days starting 2 days after the WiDr cells were subcutaneously inoculated to mice. The subcutaneous tumors were removed from mice under anesthesia after the treatment with HL and fixed in $10 \%$ formalin solution. Paraffin-embedded sections were made and detection of apoptosis was performed using the TUNEL assay according to conventional procedures.

Assessment of accumulation of HL into tumor of the murine xenograft model in vivo. The accumulation of fluorescence-labeled HL (HL/ICG) to the tumor in mice of xenograft model was observed using fluorescence macroscopic in vivo imaging system (Excitation: 725-825 nm, Emission: 790-900 nm; AEQUORIA; Hamamatsu Photonics K.K., Hamamatsu, Shizuoka, Japan). BALB/c-R/J were randomly grouped on the basis of body weight using the stratified randomization method. The number of mice was three in each group. The WiDr cells 


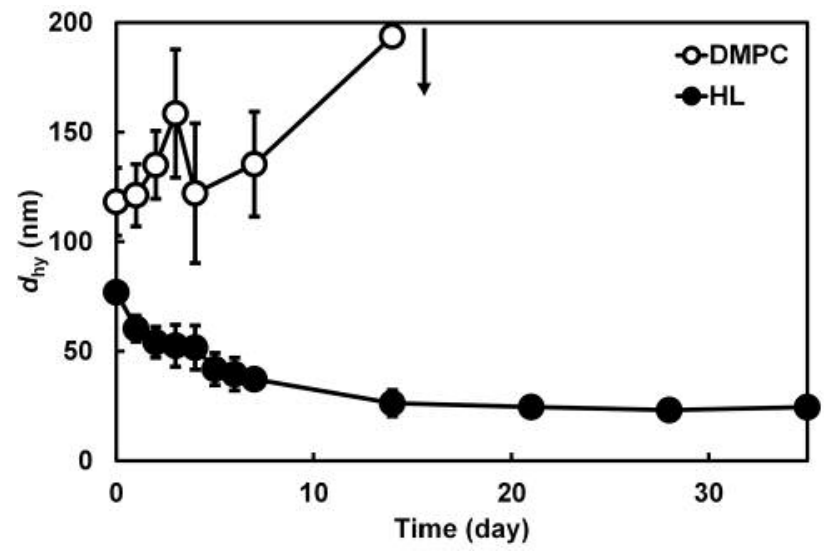

Figure 1. Time course of dhy change for HL composed of $90 \mathrm{~mol} \%$ $D M P C$ and 10 mol\% $C_{12}(E O)_{25}$ in $5 \%$ glucose solution at $25^{\circ} \mathrm{C}$, $[D M P C]=20 \mathrm{mM},\left[C_{12}(E O)_{25}\right]=2.22 \mathrm{mM}$.

$\left(5.0 \times 10^{6}\right.$ cells) were subcutaneously inoculated into the mice. HL/ICG (34 mg/kg for DMPC) was topically injected 17 days after the inoculation of WiDr cells. After the injection, the tumors were noninvasively investigated at each time point $(0.5,24,48,72,97 \mathrm{~h})$ using fluorescence macroscopic in vivo imaging system.

Statistical analysis. Results are presented as mean \pm standard error (S.E.). Data were statistically analyzed using Student's $t$-test and the log-rank test. A $p$-value of less than 0.05 was considered to represent a statistically significant difference.

\section{Results}

Physical properties of $H L$. The physical properties of HL composed of DMPC and $10 \mathrm{~mol}_{\%} \mathrm{C}_{12}(\mathrm{EO})_{25}$ were examined. The diameter of HL was measured by dynamic light scattering measurement. The results are shown in Figure 1. DMPC liposomes were unstable and precipitated after 14 days. In contrast, hydrodynamic diameter under $100 \mathrm{~nm}$ of HL was kept for over one month.

Inhibitory effects of HL on the growth of WiDr cells in vitro. We examined the inhibitory effects of HL on the growth of human colorectal cancer WiDr cells on the basis of WST-8 assay. The results are shown in Figure 2. Half-maximal inhibitory concentration $\left(\mathrm{IC}_{50}\right)$ values of $\mathrm{HL}$ and DMPC liposomes on the growth of WiDr cells were $205 \pm 10 \mu \mathrm{M}$, whereas that of $\mathrm{HL}$ was $109 \pm 10 \mu \mathrm{M}$. There was a significant difference $(p<0.05)$ in $\mathrm{IC}_{50}$ values between the DMPC liposomes and HL. These results indicate that higher inhibitory effects of $\mathrm{HL}$ were obtained as compared with DMPC liposomes.

Induction of apoptosis for WiDr cells treated with HL-25 in vitro. Detection of apoptotic cells was performed by the TUNEL method. The results are shown in Figure 3. A green

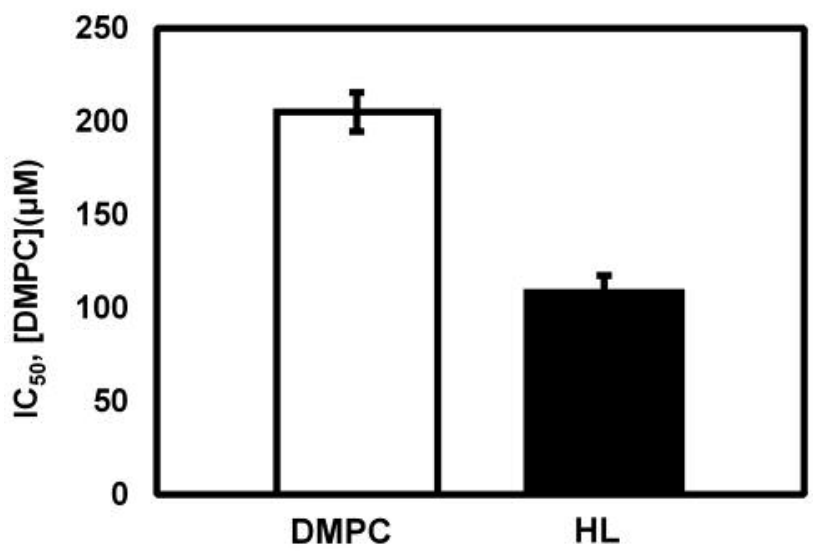

Figure 2. Half maximal inhibitory concentration $\left(I_{50}\right)$ of DMPC and $H L$ on the growth of WiDr cells for $48 h$. Data presented are mean $\pm S E$.

color, indicating induction of apoptosis, was observed in a fluorescence micrograph of WiDr cells using the TUNEL method after a 48-h treatment with HL. However, a much lower intensity of green color was observed in fluorescence micrograph of WiDr cells treated with DMPC liposomes. These results indicate that the HL induces apoptosis in WiDr cells.

Fusion and accumulation of HL into cell membranes of WiDr cells. We examined fusion and accumulation of HL (HL/ICG), including ICG as a fluorescence probe into WiDr cells, using a fluorescence cell imaging system. The results are shown in Figure 4. A significant accumulation of HL/ICG into WiDr cells was observed. Little accumulation was detected in the case of DMPC liposomes. In contrast, no accumulation of ICG was observed in WiDr cells. These results suggest that HL could selectively fuse and accumulate into WiDr cells.

Therapeutic effects of HL for the murine subcutaneous xenograft model in vivo. We examined the inhibitory effects of HL on the growth of tumors in the mouse xenograft model that was subcutaneously inoculated with WiDr cells. HL topically administered once each day for 14 days starting 2 days after the subcutaneous inoculation of WiDr cells to mice. We examined the time course of tumor volume for the HL-treated xenograft murine model. The results are shown in Figure 5. The median tumor volumes were $758.46 \pm 91.41$ $\mathrm{mm}^{3}$ and $274.25 \pm 30.17(p<0.05 v s$. control $) \mathrm{mm}^{3}$ in the control group and HL group, respectively. A notable reduction of tumor volume $(60 \%)$ was obtained in the xenograft model that was topically treated with HL without drugs after subcutaneously inoculating WiDr cells. Next, we observed the therapeutic effects of HL on this xenograft model by performing autopsy. As shown in Figure 6, reduction of tumor in HL-treated group was observed, 


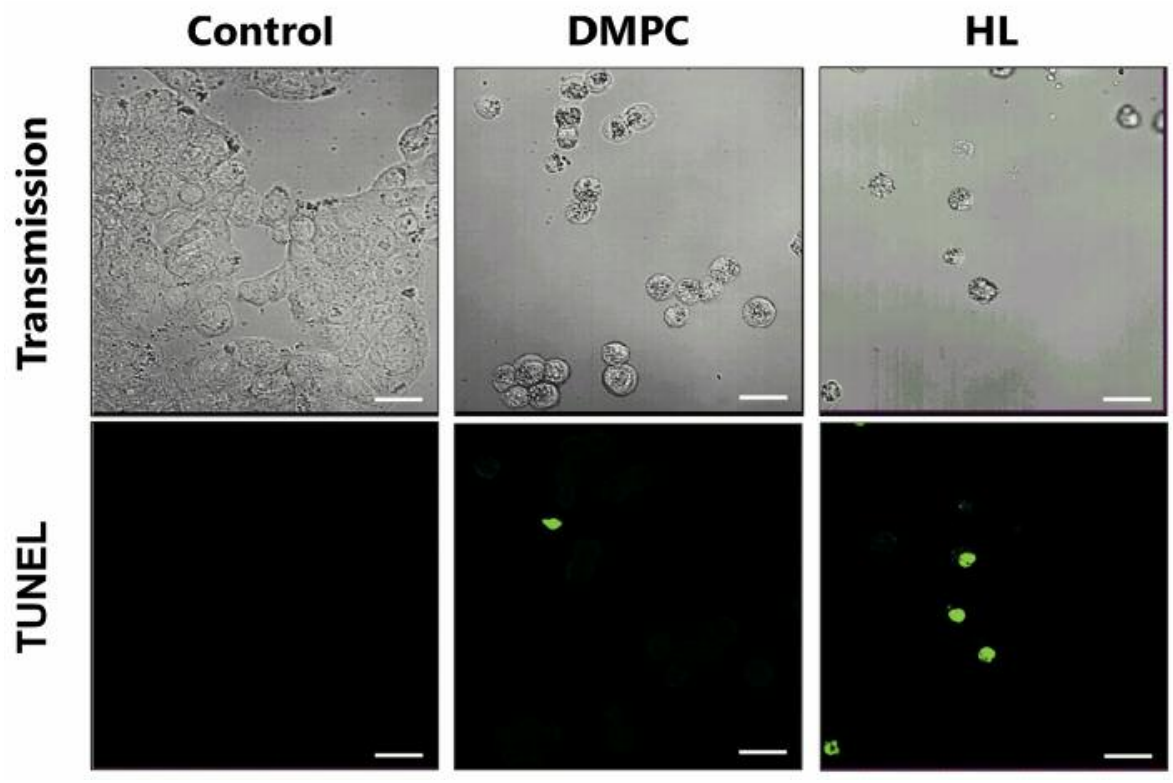

Figure 3. Fluorescence micrographs of cancer WiDr cells after treatment with HL using the TUNEL methodology for 48 . Scale bar: $20 \mu$ m, $[D M P C]=0.1 \mathrm{mM},\left[C_{12}(E O)_{25}\right]=0.011 \mathrm{mM}$.

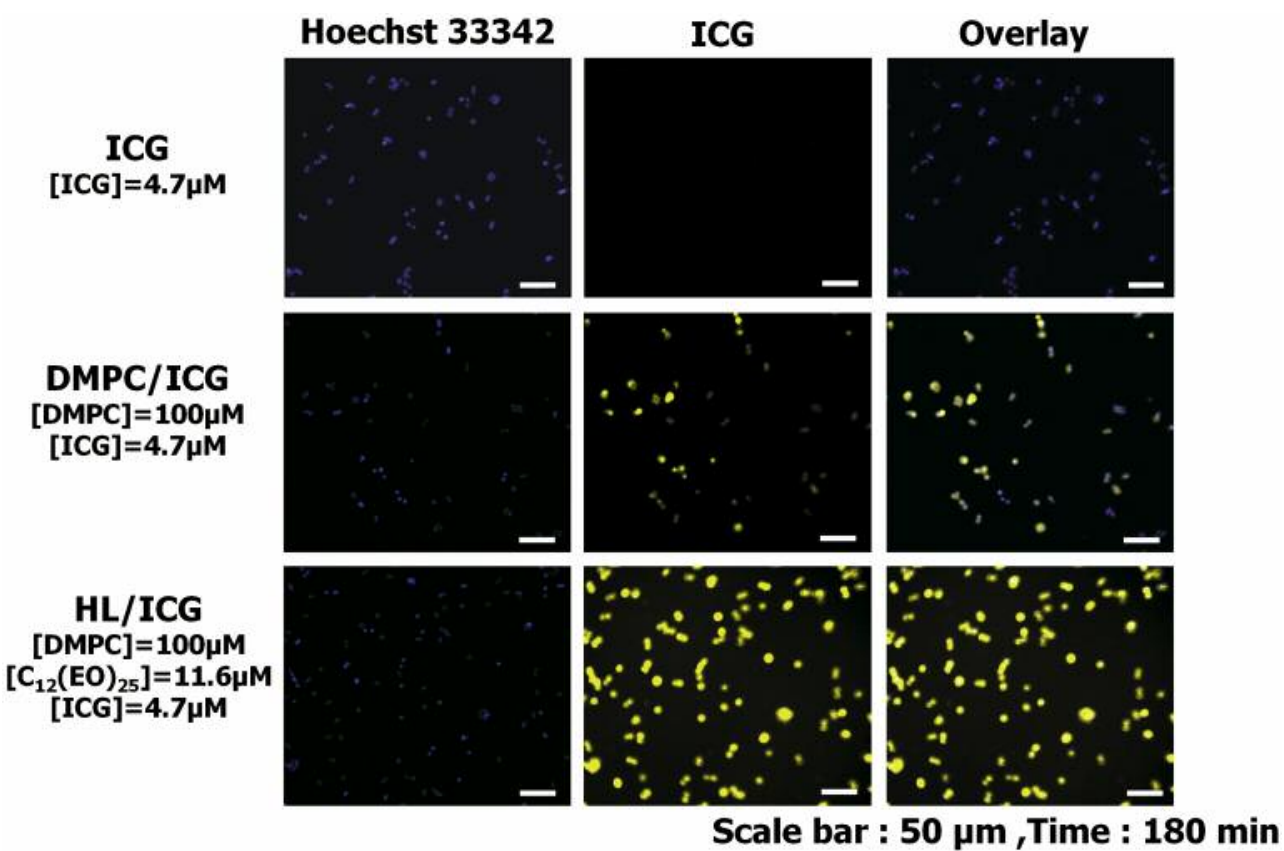

Figure 4. Selective fusion and accumulation of HL, including ICG, into the plasma membranes of WiDr cells. Scale bar: $50 \mu m$, reaction time: 3 h, $[D M P C]=0.1 \mathrm{mM},\left[C_{12}(E O)_{25}\right]=0.012 \mathrm{mM},[I C G]=0.0047 \mathrm{mM}$.

although enlargement of tumor in the control group was confirmed. We next examined the tumor weight in the HLtreated xenograft murine model. The results are shown in Figure 7. Mice treated with HL $(0.20 \pm 0.08 \mathrm{~g}, p<0.05 v s$. control) had a significantly lower weight of tumor compared with the animals in control group $(0.39 \pm 0.05 \mathrm{~g})$. These results indicate that $\mathrm{HL}$ could be effective in the xenograft model in vivo. 
Induction of apoptosis by HL in the mouse xenograft model. We examined the mechanism(s) of the therapeutic effects of $\mathrm{HL}$ on the subcutaneously-inoculated mice in vivo using the TUNEL method. HL was topically administered once each day for 14 days from 2days after the WiDr cells were subcutaneously inoculated to mice. The tumor was removed from anaesthetized mice immediately after treatment. As opposed to few apoptotic cells observed in the control group, intense apoptosis was recorded in the HL-treated group (Figure 8). These results indicate that HL exerts therapeutic effects, in terms of apoptosis in vivo when using this particular murine xenograft model.

Accumulation of HL into tumor of the xenograft model in vivo. A non-invasive the accumulation of $\mathrm{HL}$ (HL/ICG), including fluorescence probe, was observed into the tumor of the xenograft model as assessed by fluorescence macroscopic in vivo imaging system. HL/ICG was topically administered when tumor volume reached $200-300 \mathrm{~mm}^{3}$ at 12 days after the inoculation of WiDr cells. The results shown in Figure 9 demonstrate a decrease of green fluorescence within $48 \mathrm{~h}$ in the xenograft model treated with ICG. On the other hand, accumulation of HL, including ICG, into the tumor of xenograft model was observed at $97 \mathrm{~h}$. These results indicate that HL could accumulate for a prolonged period of time into tumor cells in the tumor of mouse xenograft model and inhibit the growth of WiDr cells.

\section{Discussion}

Endoscopic surgery, in the case of an early stage of colorectal cancer, is performed. Abdominal operation for advanced spread colorectal cancer is widely used. Adjuvant therapies with radiation and anticancer $\operatorname{drug}(\mathrm{s})$ may be selected after surgical treatment. Combination chemotherapy is selected for advanced colorectal cancer with metastasis in cases of unresectable metastatic tissues. A metastatic lesion is identified using an imaging technique, such as PET and the MRI, since advanced colorectal cancer may be associated with metastases to lung, liver, lymph nodes. Combination chemotherapy is one of the standard treatments for advanced colorectal cancer (1-4). However, combination chemotherapy has more severe side-effects compared to chemotherapy alone due to the lack of tumor-specific treatments (1-4). Generally, combination chemotherapy has very little or no specificity, thus causing side-effects, such as hair loss and damage to the liver, kidney and bone marrow.

Fluctuation of the surface components of the cell membrane is very different from that of normal cells. The membranes of tumor cells are generally more fluid compared to normal ones. HL showed remarkably higher inhibitory effects on the growth of human colorectal cancer cells

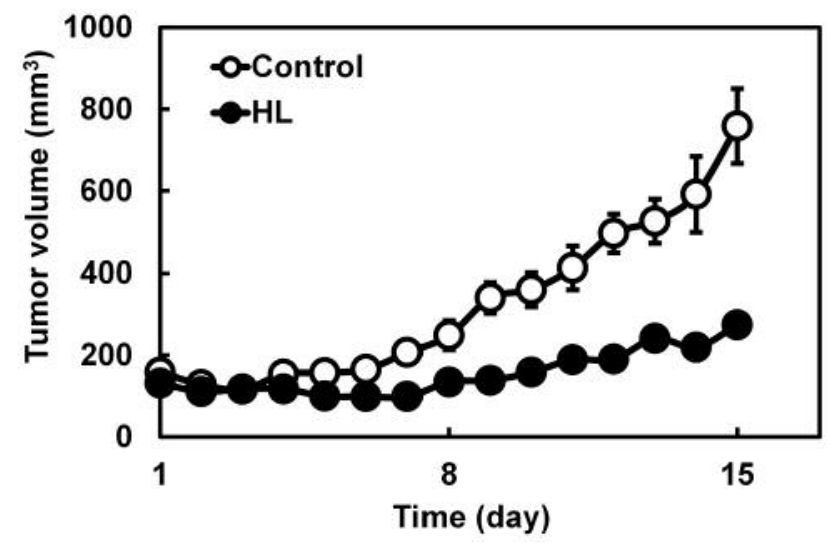

Figure 5. Suppression of tumor volume in the murine xenograft model topically treated with HL after subcutaneous inoculation of WiDr cells. Data represent the mean \pm SE $(n=7)$. Dose for DMPC $=34 \mathrm{mg} / \mathrm{kg}$, $*$ Significant difference from $(p<0.05)$ from control as calculated by the Student's t-test.

compared to DMPC liposomes in which membrane fluidity was smaller than that of HL (22). Fusion and accumulation of HL into tumor WiDr cells without affecting the normal colon CCD33Co cells using total reflection fluorescence microscopy have been reported (22). These results suggest that HL should be distinguished between normal and tumor cells on the basis of fluidity of cell membrane.

According to the morphology of HL, HL under $100 \mathrm{~nm}$ in diameter could avoid the reticular endothelial system (RES) (23) and be appropriate for intravenous administration in vivo and clinical applications.

Most animal cells can also be suicidal. One such physiological cell suicide process is termed apoptosis or programmed cell death. It is well-known that apoptosis plays an important role in many aspects of normal development and is required for maintaining homeostasis in tissues. Therefore, control of apoptosis is an important potential target for cancer chemotherapy.

We examined the antitumor effects of HL without any drug on the growth of human colorectal cancer WiDr cells in vitro. $\mathrm{IC}_{50}$ values of $\mathrm{HL}$ on the growth of WiDr cells were remarkably lower than that of DMPC liposomes. The induction of apoptosis by HL was verified in vitro for WiDr by the TUNEL method. The pathways of apoptosis induced by $\mathrm{HL}$ of $\mathrm{DMPC} / 10 \mathrm{~mol}^{2} \mathrm{C}_{12}(\mathrm{EO})_{10}$ in the human promyelocytic leukemia HL-60 has already been reported (11). HL fused and accumulated in HL-60 cell membranes. There are two pathways of apoptosis induced by HL: (i) The apoptotic signal first passes through the mitochondria, then caspase- 9 and caspase- 3 and, finally, reaches the nucleus. (ii) The apoptotic signal first passes through FAS, then caspase8 and caspase- 3 and, ultimately, reaches the nucleus. The 

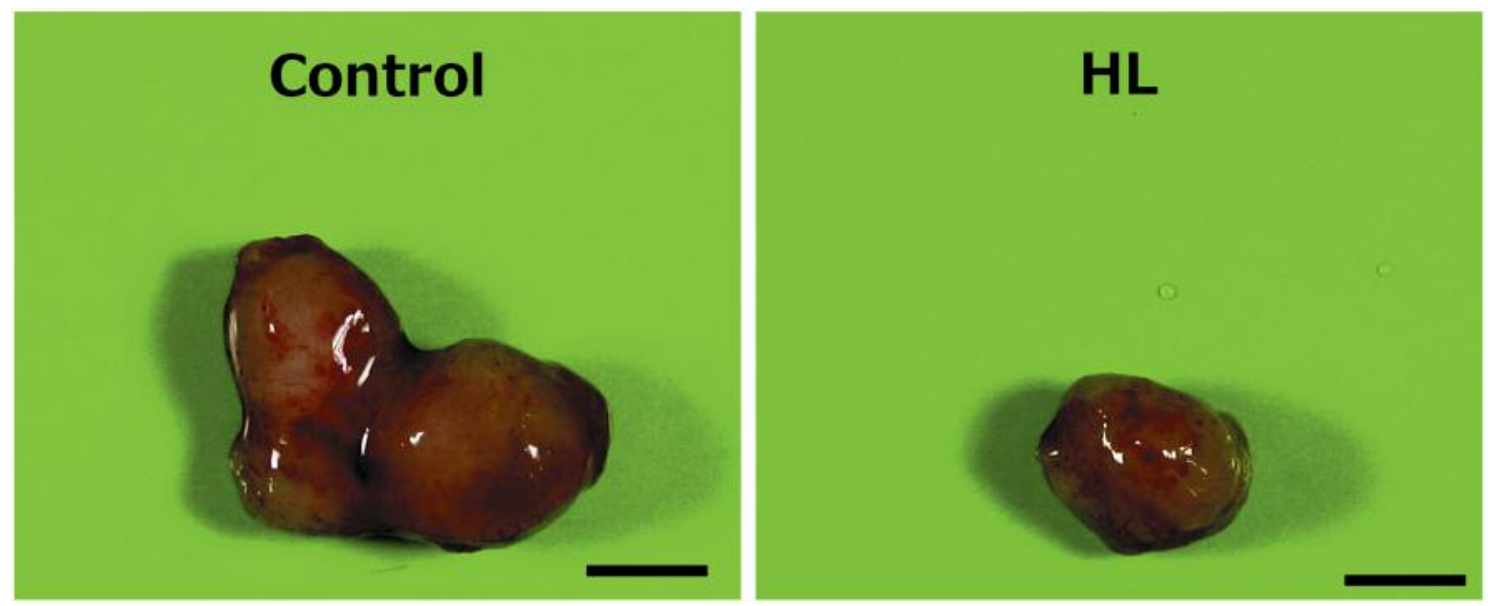

Figure 6. Photographs of tumor in mice topically treated with HL after subcutaneous inoculation of WiDr cells. Scale bar: 5 mm.

apoptotic signal by HL for WiDr cells could pass through mitochondria and activation of caspase- $-9,-8$ and -3 and, then, reach the nucleus following these two pathways. On the other hand, no induction of apoptosis was observed in WiDr cells treated with DMPC liposomes.

We investigated fusion and accumulation of $\mathrm{HL}$ (HL/ICG), including ICG as a fluorescence probe into WiDr cells, using a fluorescence cell imaging system. A significant accumulation of HL/ICG into WiDr cells was obtained. In contrast, little accumulation was detected in the case of DMPC liposomes, suggesting that HL could selectively fuse and accumulate into WiDr cells.

Next, we examined the therapeutic effects of HL using subcutaneously-inoculated colorectal cancer cells in vivo into the mouse xenograft model used in this study. Reduction of tumor in the HL-treated group was observed, although enlargement of tumor in control and DMPC groups was confirmed on the basis of volume, weight and autopsy. Many apoptotic cells were observed in the tumor section of the HLtreated group as assessed by the TUNEL method.

We, finally, examined the accumulation of $\mathrm{HL}$ ( $\mathrm{HL} / \mathrm{ICG})$, including a fluorescence probe into the tumor of the murine xenograft model, using a fluorescence macroscopic in vivo imaging system. Interestingly, long-term accumulation of HL, including ICG into the tumor of the subcutaneously inoculated xenograft model, was obtained. The aforementioned results suggest that, by employing the mouse xenograft model, HL could selectively accumulate into WiDr cells in the subcutaneously inoculated colorectal cancer cells and inhibit the growth of these cells.

No side-effects of HL in chronic toxicity test using healthy rats have been reported in vivo (12). We have already reported the pharmacokinetics of HL using normal mice and rats $(12,24-25)$, where HL circulated in blood for $3 \mathrm{~h}$ after

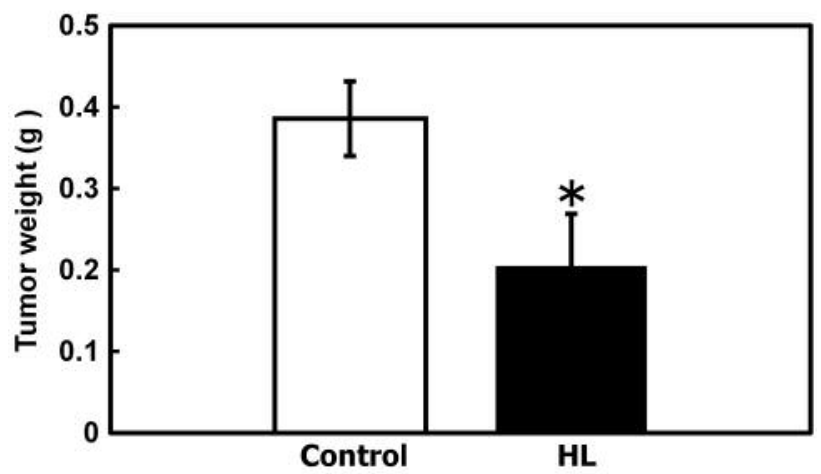

Figure 7. Suppression of tumor weight in the xenograft model topically treated with HL after subcutaneous inoculation of WiDr cells. Data represent the mean \pm SE $(n=7)$, *Significant difference from $(p<0.05)$ from control as assessed by the Student's t-test.

intravenous administration to normal mice and, then, metabolized in the liver $(24,25)$.

In clinical application, a prolonged survival of more than one year was attained in one patient with late-stage lymphoma after an intravenous injection of HL without any side-effects. In addition, a remarkable reduction of the lymph node neoplasm (solid tumor) was observed after local administration (2 times/week) of HL (12). These results suggest that HL could be a novel agent without severe sideeffects as a chemotherapy regimen in colorectal cancer.

\section{Conclusion}

We clearly demonstrated, for the first time, that noteworthy therapeutic effects along with apoptosis can be obtained in vivo concerning HL treatment of a murine xenograft model 


\section{Control}

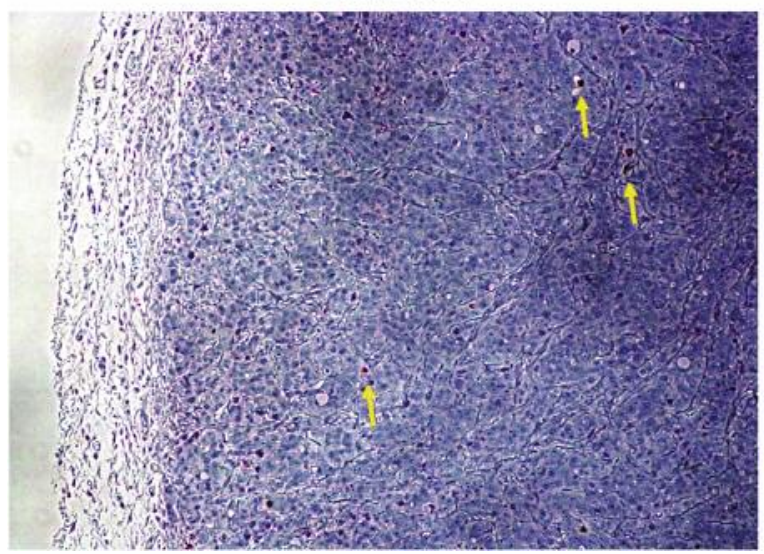

HL

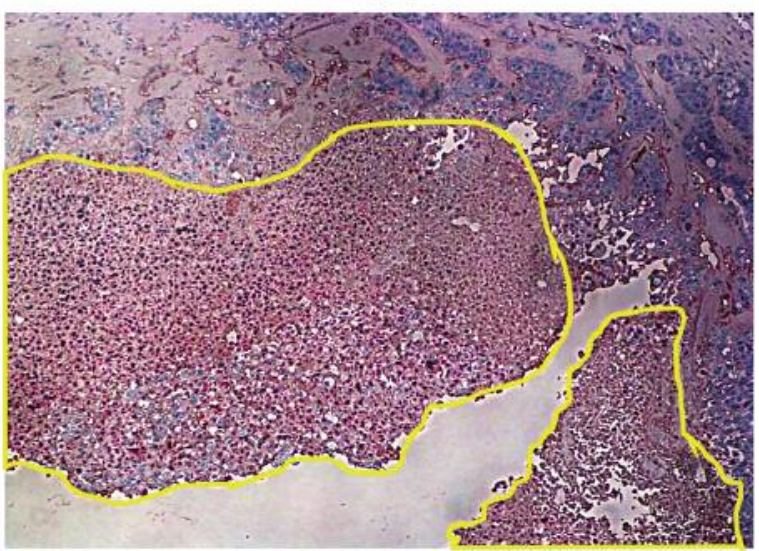

Figure 8. Micrographs of tumor in the murine xenograft model after treatment with HL using the TUNEL method. Arrows and circles indicate apoptotic cells.
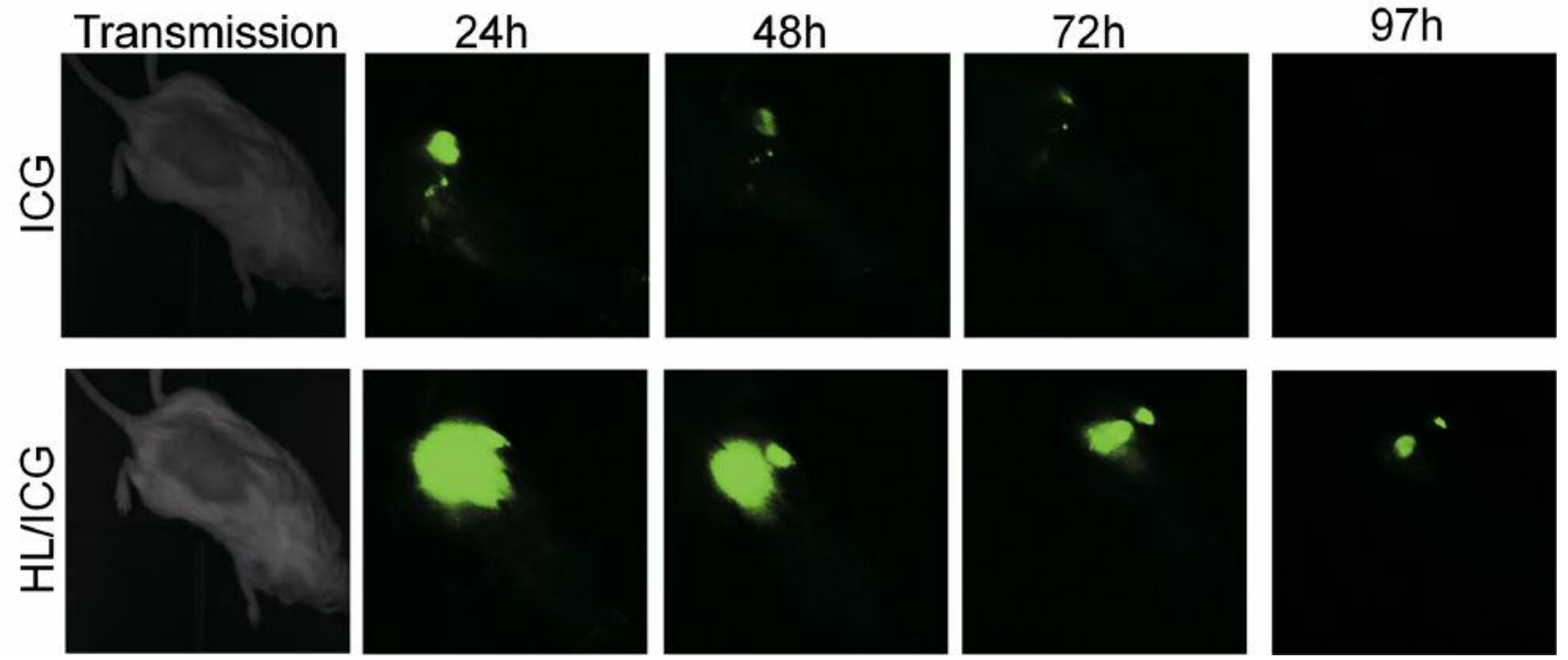

Figure 9. Accumulation of HL, including ICG, for a prolonged period into the tumor of the murine xenograft model.

with colorectal cancer cells. The important aspects of this issue are as follows: (a) HL having hydrodynamic diameter under $100 \mathrm{~nm}$ was successfully preserved over 4 weeks. (b) High inhibitory effects of HL on the growth of WiDr cells were obtained as compared with that of DMPC in vitro. (c) HL induced apoptosis in WiDr cells in vitro. (d) Remarkably high therapeutic effects of HL were obtained in the aforementioned model system as demonstrated by autopsy, tumor volume and tumor weight in vivo. (e) Induction of apoptosis was observed in the herein employed xenograft model with colorectal cancer cells after HL administration as shown by the TUNEL method. (f) Accumulation of HL, including ICG, for a prolonged time period into the tumor of xenograft model was obtained, thus suggesting that HL could provide a promising therapy and diagnosis for cancer. The results of this study can contribute to the development of chemotherapeutic regimes for patients with colorectal cancer in future clinical applications.

\section{Acknowledgements}

This work was supported, in part, by a Grant-in-Aid for Science Research from the Ministry of Education, Science and Culture of Japan (Nos. 25289299 and 25420843). 


\section{References}

1 Tournigand C, Chibaudel B, Samson B, Scheithauer W, Vernerey D, Mésange P, Lledo G, Viret F, Ramée JF, Tubiana-Mathieu N, Dauba J, Dupuis O, Rinaldi Y, Mabro M, Aucoin N, Latreille J, Bonnetain F, Louvet C, Larsen AK, André T1 and de Gramont A: Bevacizumab with or without erlotinib as maintenance therapy in patients with metastatic colorectal cancer (GERCOR DREAM; OPTIMOX3): a randomised, open-label, phase 3 trial. Lancet Oncol 16: 1493-1505, 2015.

2 Aridome K, Mori SI, Baba K, Yanagi M, Hamanoue M, Miyazono F, Tokuda K, Imamura H, Ogura Y, Kaneko K, Kijima F, Maemura K, Ishigami $S$ and Natsugoe S: A phase II, randomized study of aprepitant in the prevention of chemotherapy-induced nausea and vomiting associated with moderately emetogenic chemotherapies in colorectal cancer patients. Mol Clin Oncol 4: 393-398, 2016.

3 Leone F, Marino D, Cereda S, Filippi R, Belli C, Spadi R, Nasti G, Montano M, Amatu A, Aprile G, Cagnazzo C, Fasola G, Siena S, Ciuffreda L, Reni M and Aglietta M: Panitumumab in combination with gemcitabine and oxaliplatin does not prolong survival in wildtype KRAS advanced biliary tract cancer: A randomized phase 2 trial (Vecti-BIL study). Cancer 122: 574-581, 2016.

4 Said R, Ye Y, Hong DS, Naing A, Falchook G, Fu S, Wheler JJ, Piha-Paul $\mathrm{S}$ and Tsimberidou AM: Phase I clinical trial of lenalidomide in combination with 5-fluorouracil, leucovorin, and oxaliplatin in patients with advanced cancer. Cancer Chemother Pharmacol 77: 575-581, 2016.

5 Ueoka R, Moss RA, Swarup S, Matsumoto Y, Strauss G and Murakami Y: Extraordinary micellar enantioselectivity coupled to altered aggregate sturucture. J Am Chem Soc 107: 2185-2186, 1985.

6 Ueoka R, Matsumoto Y, Robert A. Moss, Shanti Swarup, Sugii A, Harada K, Kikuchi J and Nurakami Y: Membrane matrix for the hydrolysis of amino acid esters with marked enantioselectivity. J Am. Chem Soc 110: 1588-1595, 1988.

7 Kitamura I, Kochi M, Matsumoto Y, Ueoka R, Kuratsu J and Ushio Y: Intrathecal chemotherapy with 1,3-bis(2-chloroethyl)1-nitrosourea encapsulated into hybrid liposomes for meningeal gliomatosis: an experimental study. Cancer Res 56: 3986-3992, 1996.

8 Yukihara M, Ito K, Tanoue O, Goto K, Matsushita T, Matsumoto Y, Masuda M, Kimura S and Ueoka R: Effective drug delivery system for duchenne muscular dystrophy using hybrid liposomes including gentamicin along with reduced toxicity. Biol Pharm Bull 34: 712-716, 2011.

9 Matsumoto Y, Kato T, Kemura Y, Tsuchiya M, Yamamoto Y and Ueoka R: Intracellular resuponses of hybrid liposomes against leukemia cells related to apoptosis with antitumor activity. Chem Lett 28: 53-54, 1999.

10 Iwamoto Y, Matsumoto Y and Ueoka R: Induction of apoptosis of human lung carcinoma cells by hybrid liposomes containing polyoxyethylenedodecyl ether. Int J Pharm 292: 231-239, 2005.

11 Matsumoto Y, Iwamoto Y, Matsushita T and Ueoka R: Novel mechanism of hybrid liposomes-induced apoptosis in human tumor cells. Int J Cancer 115: 377-382, 2005.
12 Ichihara H, Nagami H, Kiyokawa T, Matsumoto Y and Ueoka R: Chemotherapy using hybrid liposomes along with induction of apoptosis. Anticancer Res 28: 1187-1195, 2008.

13 Shimoda S, Ichihara $\mathrm{H}$, Matsumoto $\mathrm{Y}$ and Ueoka R: Chemotherapy with hybrid liposomes for human breast tumors along with apoptosis in vivo. Int J Pharm 372: 162-168, 2009.

14 Ichihara H, Matsuoka Y, Matsumoto Y and Ueoka R: Therapeutic effects of hybrid liposomes on the growth of gastric carcinoma involve apoptosis. Anticancer Res 30: 2011-2016, 2010.

15 Kitajima H, Komizu Y, Ichihara H, Goto K and Ueoka R: Hybrid liposomes inhibit tumor growth and lung metastasis of murine osteosarcoma cells. Cancer Med 2: 267-276, 2013.

16 Nakano K, Iwamoto Y, Takata W, Matsumoto Y, Ueoka R: Specific accumulation and growth inhibitory effects of hybrid liposomes to hepatoma cells in vitro. Bioorg Med Chem Lett 12: 3251-3254, 2002.

17 Ishiyama M, Miyazono Y, Sasamoto K and Ohkura Y and Ueno $\mathrm{K}$ : A highly water-soluble disulfonated tetrazolium salt as a chromogenic indicator for NADH as well as cell viability. Talanta 44: 1299-1305, 1997.

18 Tominaga H, Ishiyama M, Ohseto F, Sasamoto K, Hamamoto T, Suzuki K and Watanabe M: A water-soluble tetrazolium salt useful for colorimetric cell viability assay. Anal Commun 36: 47-50, 1999.

19 Ono A, Hattori S, Kariya R, Iwanaga S, Taura M, Harada H, Suzu $\mathrm{S}$ and Okada S: Comparative study of human hematopoietic cell engraftment into BALB/c and C57BL/6 strain of rag-2/jak3 doubledeficient mice. J Biomed. Biotechnol 2011: 539748-1-6, 2011.

20 Inaba M, Sato S, Yamori T, Tashiro T, Ohnishi Y, Maruo K, Ueyama $\mathrm{Y}$ and Tsuruo $\mathrm{T}$ : Anticancer activities of orally administered menogaril against human stomach and breast cancers implanted in mude mice. Anticancer Res 12: 1953-1956, 1992.

21 Banciu M, Metselaar JM, Schiffelers RM and Storm G: Antitumor activity of liposomal prednisolone phosphate depends on the presence of functional tumor-associated macrophages in tumor tissue. Neoplasia 10: 108-117, 2008.

22 Komizu Y, Matsumoto Y and Ueoka R: Membrane targeted chemotherapy with hybrid liposomes for colon tumor cells leading to apoptosis. Bioorg Med Chem Lett 16: 6131-6134, 2006.

23 Huang SK1, Lee KD, Hong K, Friend DS and Papahadjopoulos D: Microscopic localization of sterically stabilized liposomes in colon carcinoma-bearing mice. Cancer Res 52: 5135-5143, 1992.

24 Ichihara H, Nagami H, Yamamoto K, Matsumoto Y and Ueoka R: Chemotherapy with hybrid liposomes without any drug in vivo. Yakugaku Zasshi 123: 25-34, 2003. (Japanese)

25 Ichihara H, Hino M, Umebayashi M, Matsumoto Y and Ueoka $\mathrm{R}$ : Intravenous injection of hybrid liposomes suppresses the liver metastases in xenograft mouse models of colorectal cancer in vivo, Eur J Med Chem 57: 143-148, 2012. 